\title{
Implementação do Laboratório de Ensino de Matemática em Escolas de Educação Básica: repensando o processo de ensino e aprendizagem
}

\author{
Implementation of the Mathematics Teaching Laboratory in Basic \\ Education Schools: rethinking the teaching and learning process
}

\author{
Elizangela Weber (elizangela.weber@iffarroupilha.edu.br) \\ Licenciatura em Matemática - IF Farroupilha, Campus Santa Rosa. \\ João Sidinei Marostega (jsmarostega@ yahoo.com.br) \\ Licenciatura em Matemática - IF Farroupilha, Campus Santa Rosa. \\ Lucilaine Goin Abitante (lucilaine.abitante@iffarroupilha.edu.br) \\ Licenciatura em Matemática - IF Farroupilha, Campus Santa Rosa. \\ Mariele Josiane Fuchs (mariele.fuchs@iffarroupilha.edu.br) \\ Licenciatura em Matemática - IF Farroupilha, Campus Santa Rosa.
}

\begin{abstract}
Resumo:
O Laboratório de Ensino de Matemática (LEM) tem sido objeto de estudo de várias pesquisas que buscam apontar as contribuições deste espaço para o ensino e aprendizagem da matemática. Como a maioria dos estudos tem se desenvolvido na direção da importância do LEM na formação inicial e continuada de professores, buscou-se a implementação deste espaço numa Escola de Educação Básica com o objetivo de vislumbrar aspectos significativamente positivos para o ensino da matemática a partir da experimentação destes materiais e instrumentos, além de verificar como seria a receptividade da direção, professores e alunos para esta proposta. Assim, decorridos três anos da sua organização, retornou-se a escola com uma pesquisa a fim de verificar se o laboratório encontrava-se preservado e utilizado por alunos e professores, além de saber quais foram as contribuições para o ensino de matemática. E, transcendendo os objetivos do projeto, constatou-se que a experiência do LEM serviu de trampolim para uma reorganização pedagógica da escola, contemplando laboratórios para as demais áreas do conhecimento. Porém, ficou manifestada a necessidade de formação continuada, a importância de trocar experiências e conhecer materiais que são desenvolvidos e pesquisados pela comunidade acadêmica, buscando um ensino contextualizado, prazeroso e significativo para os alunos.
\end{abstract}

Palavras-chave: LEM; Experimentação; Ensino e Aprendizagem de Matemática.

\section{Abstract:}

The Laboratory of Mathematical Teaching (LME) has been the object of study of several researches that seek to point out the contributions of this space to the teaching and learning of mathematics. As the most of the studies have developed in the direction of the importance of the LME in the initial and continuous formation of teachers, we sought the implementation of this space in a School of Basic Education with the 
objective to glimpse significantly positive aspects for the teaching of mathematics from the experimentation of these materials and instruments, besides verifying how the receptivity of the school principal, teachers, and students to this proposal would be. So, after three years of its organization, we returned to school with a research, in order to verify if the laboratory was preserved and it was used by students and teachers, besides knowing what the contributions to mathematics teaching were. And, transcending the objectives of the project, it was verified that the experience of the LME served as a springboard to a pedagogical reorganization of the school, providing opportunities to use the laboratories to the other areas of knowledge. However, it was manifested the need for continuous training, the importance of exchanging experiences and knowing materials that are developed and researched by the academic community, seeking contextualized, enjoyable and meaningful teaching to the students.

Key-words: LME; Experimentation; Teaching and Learning of Mathematics.

\section{INTRODUÇÃO}

Com a evolução das práticas de ensino e das tecnologias, ensinar Matemática tem se tornado uma tarefa cada vez mais desafiadora, considerando que ainda há certa rejeição da disciplina por parte de alguns alunos. No entanto, é preciso buscar alternativas pedagógicas que possam minimizar estas dificuldades diagnosticadas ao longo do tempo, possibilitando alcançar uma aprendizagem significativa.

O ensino da Matemática, em dias atuais, requer do professor não apenas o conhecimento específico dos conceitos trabalhados, mas o uso de metodologias de ensino e atividades diferenciadas mais eficientes. Neste sentido, evidencia-se a importância do Laboratório de Ensino de Matemática (LEM) como um ambiente para auxiliar na compreensão de conceitos, na experimentação do conhecimento e na construção do saber matemático.

Deste modo, este trabalho apresenta uma discussão teórica de pesquisadores da área acerca de contribuições do LEM para o processo de ensino e aprendizagem da Matemática, bem como de sua exploração por parte dos professores e aproveitamento de estudos dos alunos. Seguindo com o relato de uma experiência exitosa da organização do LEM em uma Escola de Educação Básica, decorrente de uma necessidade apontada por um acadêmico em formação inicial, e engajada como um projeto de extensão de uma Instituição Pública de Ensino Superior e pela direção e professores da referida Escola. 
Considerando o contexto enfrentado pelas instituições públicas tanto de valorização dos profissionais da Educação, quanto de escassos recursos destinados aos subsídios básicos de uma escola, implementar um Laboratório que conte com materiais didáticos e tecnológicos, foi um grande desafio. No entanto contou-se com parcerias de profissionais da educação, empresas, acadêmicos da Licenciatura em Matemática e alunos da Educação Básica para a organização do espaço, confecção, conserto e arrecadação de materiais que constituíssem um acervo significativo para o desenvolvimento de aulas práticas de Matemática.

Conforme afirma Lorenzato (2012), o ideal é que o LEM seja a consequência da aspiração de um grupo, com a participação de diferentes segmentos da escola e assim a conquista será de professores, administradores e alunos. Conquista esta, evidenciada na Escola Estadual de Educação Básica Yeté, onde a implementação do LEM além de refletir nas aulas de Matemática, instigou a reorganização pedagógica da escola, com laboratórios para as demais áreas do conhecimento.

Além da organização do espaço do LEM nesta Escola, o trabalho busca avaliar o projeto como um todo, discutindo as contribuições pedagógicas para as aulas, as ações pedagógicas dos professores de Matemática e as dificuldades percebidas para sua consolidação. Assim, a partir de um questionário realizado com os professores de Matemática que atuam na escola, se avaliou como aconteceu a exploração do LEM, dos materiais didáticos e tecnológicos no planejamento de suas aulas, e os resultados percebidos na aprendizagem dos conceitos matemáticos.

\section{LEM - CONTRIBUIÇÕES PARA O PROCESSO EDUCATIVO COM A MATEMÁTICA}

Ao refletirmos sobre o processo educativo com a Matemática nos ambientes escolares deparamo-nos com alguns aspectos que influenciam diretamente o êxito do processo, dentre eles o desencanto dos alunos por esta área de conhecimento. Talvez este fato esteja atrelado ao modo como o processo de ensino vem sendo desenvolvido no espaço da sala de aula, pois segundo D’Ambrósio (1991, p.1) “[...] há algo errado com a matemática que estamos ensinando, o conteúdo que tentamos passar adiante através dos sistemas escolares é obsoleto, desinteressante e inútil”. 
O entendimento de D’Ambrósio (1991) frente a esta situação sintetiza o pensamento geral dos alunos em relação à Matemática, disciplina descrita pela maioria deles, como algo incompressível, que traz consigo alto índice de reprovação, devido às fórmulas complexas e sem ligação com o cotidiano. Muitos alunos não compreendem os conceitos matemáticos pelo fato de não haver uma relação entre o conhecimento que esses alunos trazem consigo e o conteúdo tratado em sala de aula.

Nesse sentido, torna-se importante desmistificar a Matemática mediante a proposição de um processo de ensino que facilite a construção da aprendizagem com significado. Este é o caminho para desconstruir algumas crenças e mitos que ainda permanecem vivas abismando esta área do conhecimento, bem como inibir processos de reprodução de grafismos sem significado para o aluno.

É preciso incorporar ao trabalho docente desenvolvido no contexto escolar a verdadeira função da escola, com vistas a

[...]ativar as estruturas lógico-matemáticas, linguísticas, espaço temporais e sócio afetivas do aluno, para que ele questione, compreenda e atue sobre o mundo, privilegiando os códigos da linguagem escrita, gráfica, falada e matemática. Assim, ele terá melhores condições para atitudes construtivas, por meio de um dialética que o ligue às situações socialmente elaboradas (QUEIROZ, 2011, p.32).

Portanto, os espaços escolares anseiam pelo desenvolvimento de atividades em que os alunos possam prever, conjecturar, exercitar o levantamento de hipóteses, processos estes que o ensino de Matemática, muitas vezes, vem negligenciando em troca de uma imagem de exatidão (LORENZATO, 2008) e de pouca aplicabilidade em situações cotidianas.

Tal distanciamento entre o que se ensina e o que se aprende, se caracteriza por vezes por uma ação docente que prioriza o trabalho dos conceitos matemáticos a partir de uma linguagem formal, seguidos de treinamento de técnicas operatórias para resolução de exercícios. Esta abordagem acarreta em uma série de dificuldades de compreensão e assimilação do conteúdo, em virtude da teoria não estar relacionada com a realidade do aluno.

Considerando estas discussões, faz-se necessário a busca por estratégias pedagógicas no ensino de Matemática pautadas em novos paradigmas em relação ao processo de aprendizagem. Paradigmas estes que compreendam a necessidade de 
criação de situações contextualizadas que permitam o desenvolvimento de processos mentais pelos alunos e despertem neles, habilidades para resolver problemas e tomar decisões, favorecendo o aprendizado.

O processo de aprendizagem em Matemática, segundo os Parâmetros Curriculares Nacionais (BRASIL, 2000), deveria incorporar situações para os educandos que despertasse sua inteligência ao resolverem problemas, ao tomarem decisões, bem como permitissem a aquisição de processos mentais indispensáveis para a evolução do pensamento matemático. Quando a escola trabalha com essa perspectiva, favorece o aluno a construir e reconstruir o seu conhecimento, melhorando consequentemente o seu aproveitamento nas atividades matemáticas (SÁ et al., 2014).

Estudos no campo da educação matemática apontam que a assimilação de conceitos e a aprendizagem da abstração matemática é potencializada quando o processo de ensino é desencadeado do concreto para o abstrato. Lorenzato (2008, p.15) compartilha dessa ideia ao pontuar que "palavras não alcançam o mesmo efeito que conseguem os objetos ou imagens, estáticos ou em movimento. Palavras auxiliam, mas não são suficientes para ensinar". Embora não seja suficiente para que a abstração matemática aconteça, o concreto é necessário para a aprendizagem pois mobiliza os conhecimentos prévios dos alunos, estabelecendo uma rede de negociações de signos e sentidos, para alcançar a abstração.

Desse modo, a inserção de atividades de experimentação nas práticas docentes apresentam-se como potenciais à medida que permitem ao aluno se envolver com o assunto em estudo, investigar as situações propostas, levantar hipóteses e buscar estratégias para encontrar uma solução, valorizando o processo de construção do saber. Inicialmente, a experimentação pode ser concebida como ação sobre objetos (manipulação), com valorização da observação, comparação, montagem, decomposição (separação), distribuição. Mas a importância da experimentação reside no poder que ela tem de conseguir provocar raciocínio, reflexão, construção de conhecimento, sendo "[...] a melhor maneira para se conseguir a aprendizagem com significado, uma vez que ela realça o 'porquê', a explicação e, assim, valoriza a compreensão" (LORENZATO,2008, p.72).

A utilização da experimentação traz implicações para o trabalho docente visto que exige do professor 
[...] um conhecimento aprofundado do assunto a ser apreendido pelos alunos, que os objetivos da aula estejam claramente definidos, que as estratégias de ensino estejam adequadas ao nível de desenvolvimento dos alunos e que os materiais didáticos estejam disponíveis ou sejam produzidos ou, até mesmos, inventados (LORENZATO, 2008, p.80).

Sendo assim, a transposição didática do professor envolvendo a experimentação precisa estar ancorada no conhecimento sobre o conceito, na delimitação de suas intencionalidades/objetivos e na seleção de materiais considerando o contexto da turma em que desencadeará o processo de ensino. Vale dizer que neste processo, os materiais concretos emergem como instrumentos valorosos e, como afirma Lorenzato (2012), exercem grande influência nos processos de ensino e aprendizagem, já que conseguem transpor do teórico para o concreto, problemas encontrados na matemática, auxiliando o aluno a assimilar esse conhecimento através do raciocínio lógico crítico e científico.

Mediante as potencialidades do uso de materiais concretos no processo de aprendizagem da Matemática, considerando as necessidades/demandas de ensino no contexto atual, decorre uma inescapável necessidade de as escolas possuírem laboratórios de ensino dotados de uma diversidade de materiais didáticos.

Acredita-se nas contribuições do LEM para o processo educativo com a Matemática visto que, além de abrigar um acervo de materiais, possibilita a organização, planejamento e execução das atividades matemáticas atreladas à experimentação e análise por parte do aluno e, consequentemente, a construção do seu conhecimento. O LEM, como defende Lorenzato (2012, p.7), constitui-se como “[...] uma sala-ambiente para estruturar, organizar, planejar e fazer acontecer o pensar matemático, [...] para facilitar, tanto ao aluno como ao professor, questionar, conjecturar, procurar, experimentar, analisar e concluir, enfim, aprender [...]”.

Nesta perspectiva, a organização de um (LEM) pode ser constituído de materiais ou equipamentos como:

[...] sólidos, figuras, quebra-cabeças, modelos (réplicas) estáticos ou dinâmicos, instrumentos de medida, livros, revistas, quadros murais, coletâneas de problemas, de questões de vestibulares, de falácias e de episódios de história da matemática, transparências, fitas, filmes, softwares, calculadoras, computadores (LORENZATO, 2008, p.112).

Este acervo que pode tanto ser adquirido, ou dentro de uma limitação, construído com materiais alternativos, é fundamental para o desenvolvimento do processo educativo com a Matemática, pois os materiais e equipamentos do LEM possibilitam 
processos de experimentação onde cada aluno desenvolve competências e habilidades a partir de seu próprio ritmo de aprendizagem, sendo respeitadas as diferenças individuais, oportunizando ao professor a identificação dos alunos que necessitem de uma orientação diferenciada. Isso, por sua vez, auxilia o professor na condução das aulas e no repensar de sua prática, de modo a desenvolver a construção do conhecimento com seus alunos.

Frente ao exposto, entende-se a importância deste espaço não somente em instituições de formação inicial, mas em escolas de Educação Básica, onde o professor possa explorar as potencialidades do LEM, desenvolvendo um ensino que proporcione aos seus alunos uma aprendizagem significativa e condizente com o contexto onde estão inseridos. Para tanto foi desenvolvido um projeto de extensão para a implementação de um LEM junto a uma Escola Pública do município de Tuparendi/RS, Escola Estadual de Educação Básica Yeté, com o propósito de dinamizar o processo de ensino e aprendizagem da Matemática.

\section{LEM - IMPLEMENTAÇÃO DESTE ESPAÇO NA ESCOLA DE EDUCAÇÃO BÁSICA}

No período entre 2014 e 2015, durante o desenvolvimento do Estágio Curricular Supervisionado de um acadêmico da Licenciatura em Matemática na Escola Estadual de Educação Básica Yeté, vislumbrou-se a possibilidade de desenvolver um projeto de extensão que pudesse contribuir com a ressignificação do ensino de Matemática naquela escola. Percebendo quanto os materiais, metodologias e tecnologias contribuíram para a aprendizagem dos alunos e que a escola não dispunha de um espaço onde pudessem ser deixados os materiais utilizados durante o estágio, nem um laboratório de informática em perfeito funcionamento para que fossem instalados os softwares, emergiu a ideia de um projeto que trouxe mudanças importantes para a escola.

O desejo de contribuir de alguma maneira com a escola se uniu a um propósito maior, a construção/organização de um espaço dentro da mesma que oportunizasse a descoberta de novas formas de construção do saber matemático, tanto por parte do aluno como do professor, seja com materiais manipulativos, jogos ou tecnologias. Começa então a idealização do Laboratório de Ensino de Matemática (LEM). 
A partir de uma conversa, na época, com a orientadora do Estágio Curricular Supervisionado, definiu-se que o projeto do LEM começasse a ganhar forma através de um projeto de extensão do próprio Instituto Federal Farroupilha, atribuindo credibilidade a proposta, além de um caráter formal, para que pudesse ser apresentado àquela comunidade escolar.

$\mathrm{Na}$ apresentação do objetivo, justificativa, metodologia e resultados esperados com o projeto, a direção recebeu com entusiasmo a proposta apoiando de maneira incondicional o desenvolvimento da mesma, presenteando o projeto com um espaço físico para a construção do LEM, espaço este que na época era utilizado como depósito de classes, mesas, cadeiras e computadores sucateados.

O início dos trabalhos mostrou-se desafiador, afinal o espaço físico existente precisava ser adequado e estruturado de modo a tornar-se um lugar de construção de conhecimento, atrativo aos olhos dos alunos e motivador na visão dos professores, facilitando o desenvolvimento do processo de ensino e aprendizagem. Porém este não seria o maior desafio, pois para que o LEM pudesse realmente existir era necessário, além do apoio dos professores, direção e coordenação, o envolvimento dos alunos.

A inclusão dos alunos na construção daquele espaço seria fundamental para que toda comunidade escolar estivesse engajada no projeto. Assim, a maneira encontrada para buscar esse apoio foi através de visitas a todas as turmas do Ensino Fundamental e Médio da escola, com o objetivo de explicar como seria esse novo espaço que estava surgindo, qual sua função dentro da escola e como os alunos poderiam e deveriam participar do processo de estruturação. O resultado foi o engajamento de quatro alunas voluntárias que constituíram a "equipe" incumbida de tirar essa ideia do papel e transformá-la em algo real.

O desafio inicial havia sido vencido, os alunos adotariam esse espaço movido pela paixão dessas alunas pioneiras (Figura 1), que se dispuseram a contribuir em seu contraturno escolar com a consolidação deste espaço. 


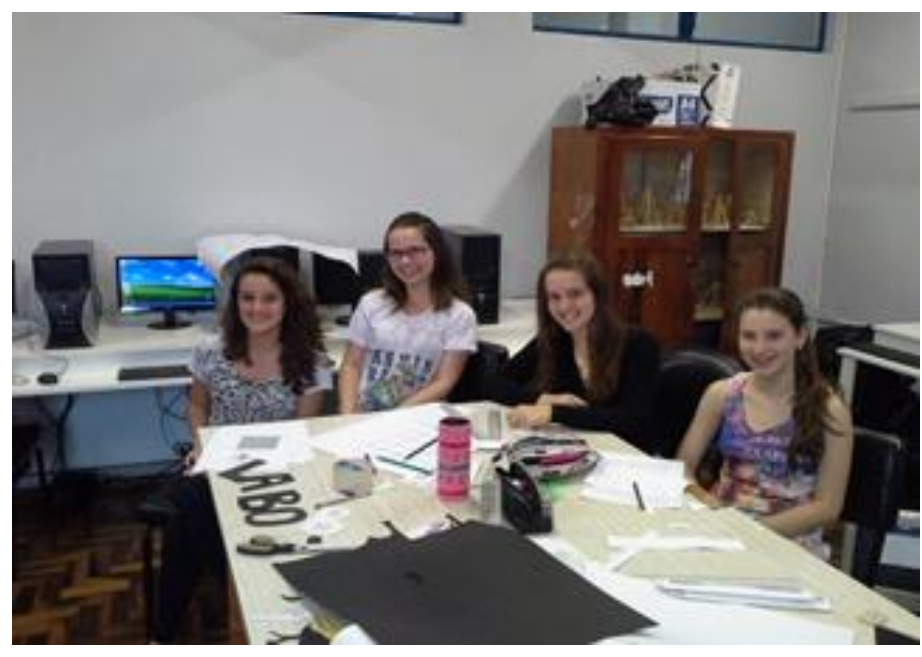

Figura 1 - Alunas colaboradoras do Projeto.

A renovação do ensino passou a ser tratado como uma necessidade, e a incorporação das quatro alunas do Ensino Médio como voluntárias ao projeto fizeram toda a diferença, pois a contribuição nas construções e organização do laboratório foi fundamental para o êxito da estruturação daquele espaço. Além do voluntariado da escola, a própria comunidade local também participou dessa construção doando sobras de madeira e ferramentas para construção de alguns materiais, peças de computador para colocar em funcionamento as máquinas estragadas que estavam depositadas naquele espaço, e a escola doando materiais de consumo utilizados na construção de jogos e materiais didáticos manipuláveis, havendo assim, uma parceria muito importante entre toda comunidade escolar e os proponentes do projeto.

Assim, organizar, limpar e consertar foram ações determinantes dos primeiros encontros da equipe que iria construir o LEM na escola.

Durante este período, devido uma aproximação com a direção de outra escola no município de Santa Rosa/RS, se soube que haviam vinte e três computadores para doação, destes, apenas dois em funcionamento. Tal doação foi acolhida com muita gratidão, sendo possível colocar no LEM doze computadores em perfeito funcionamento, os quais serviram para a inserção dos recursos tecnológicos.

Após a organização estrutural da sala passou-se para a etapa principal do projeto, ou seja, buscar através de pesquisa, os recursos didáticos, jogos e tecnologias que iriam compor o acervo de materiais do LEM. Essa pesquisa foi iniciada pelos professores de Matemática que trabalhavam na escola, a fim de entender suas necessidades e possíveis 
carências de seus alunos, norteando os trabalhos posteriores de desenvolvimento dos materiais que fariam parte desse laboratório.

Desse modo, buscou-se organizar um espaço em que os alunos pudessem questionar, conjecturar, experimentar, analisar e concluir, aprendendo matemática de maneira significativa. Para os professores, um espaço que pudesse oferecer materiais e recursos capazes de incorporar significação ao ensino de matemática, melhorando a compreensão dos conteúdos trabalhados, pois o LEM tem por objetivo unir teoria à prática, buscando preencher a lacuna existente entre a formação pedagógica e teórica (LORENZATO, 2012).

Mas se esbarrou em um problema que poderia dificultar a implementação do LEM, muito comum à maioria das escolas: não havia recurso financeiro para a compra de materiais. Então, não bastava apenas determinar os materiais adequados às necessidades dos professores, mas ter a sensibilidade de adequá-los de acordo com a realidade existente. Neste sentido, após a fase de levantamento dos possíveis materiais didáticos que poderiam ser criados, realizou-se uma análise criteriosa sobre sua aplicabilidade no ensino de matemática, sua relação com a teoria e com o contexto em que os alunos estavam inseridos. Essas informações foram colocadas em pauta na discussão com a direção da escola e professores para que sugestões fossem elencadas.

Em seguida iniciou-se a etapa da construção dos materiais, sendo organizado um cronograma a fim de delimitar as ações. A cada encontro era construído um material e apenas passava-se para a construção do próximo quando as voluntárias soubessem manipular o material construído. Isso pelo fato de que elas atuariam de modo essencial para o sucesso do LEM, já que auxiliariam no conhecimento dos alunos e suporte para os professores de matemática.

Essa construção buscou estabelecer a proximidade entre os professores, a coordenação pedagógica, direção e alunos, com o objetivo de criar a cultura da utilização dos recursos que seriam construídos no LEM. Assim os alunos eram convidados a participar de oficinas de construção dos materiais (Figura 2), formalizando a concepção de um espaço destinado à pesquisa e a construção do conhecimento, desmistificando a ideia de que o professor é o único personagem que leva o saber para a sala de aula e ressaltando que a descoberta do aluno é primordial para o sucesso da aprendizagem, pois o saber não é realizado apenas por uma via de informação. 


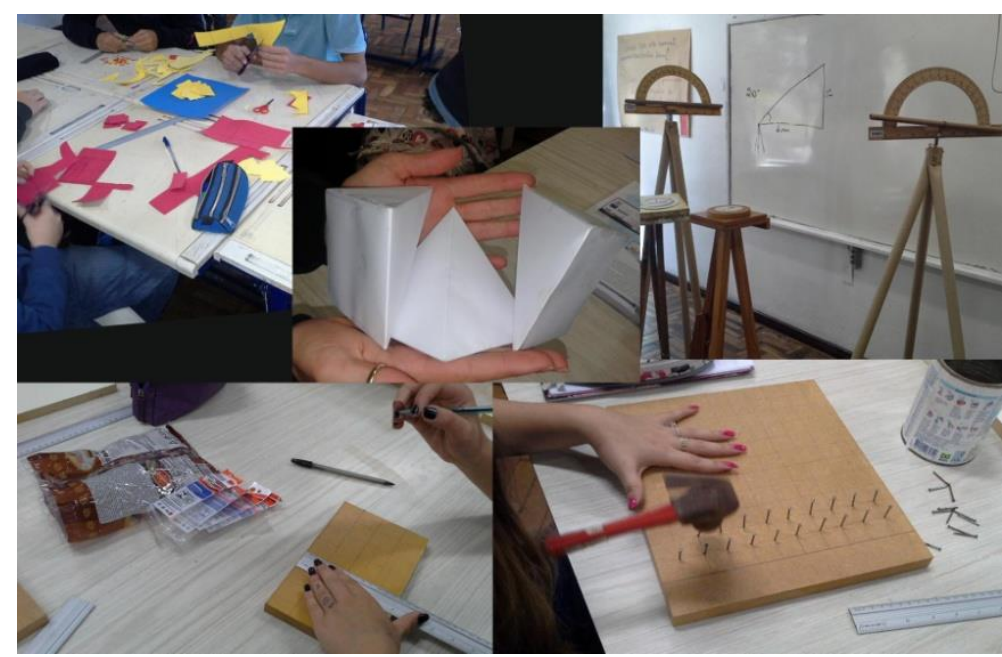

Figura 2 - Oficinas de Construção dos Materiais.

Esta proximidade dos alunos foi fundamental para o sucesso do LEM, pois sua interação com os materiais demonstrava entusiasmo pela descoberta, além da realização quando entendiam as deduções realizadas por eles mesmos.

O maior desafio não foi necessariamente a construção dos materiais didáticos, nem a organização da sala que deveria ser o LEM, muito menos a falta de recurso para compra de materiais. O maior desafio encontrado foi a quebra de paradigma quanto à utilidade do laboratório, seja entre professores ou entre alunos. Com base no que autores trazem sobre a importância do LEM na escola buscou-se apontar caminhos que pudessem desmistificar alguns entendimentos, compreendendo que a aprendizagem necessita de experiências que aliam teoria à prática para se tornar significativa.

Partindo do pressuposto de Comenius, ainda em 1650, que o conhecimento começa pelos sentidos e que só se aprende fazendo, de Locke, no século XVII, sobre a necessidade da experiência sensível para alcançar o conhecimento, de Rousseau, no final do século XVIII, afirmando que a experiência é um fator primordial a aprendizagem; complementados por Piaget (1975) que diz que a atividade intelectual não pode ser separada do funcionamento "total" do organismo, e de Vygotsky (1996), afirmando que o meio tem influência direta no sujeito, pensaram-se atividades que pudessem envolver o aprender fazendo, a experiência do fazer, o desenvolvimento da atividade intelectual e a influência que teriam na modificação dos processos de ressignificação do conhecimento. 
Assim o LABEMAT, como foi chamado na escola, foi organizado como sendo um espaço destinado à produção de recursos didáticos e pesquisa, discussão e construção de novas estratégias de ensino, descoberta de diferentes materiais manipuláveis e jogos lúdicos, utilização de diferentes metodologias atreladas aos materiais e tecnologias disponíveis naquele local, tornando um ambiente propício à descoberta, além de ser um espaço de formação de futuros professores assim como de formação continuada, conforme nos apresenta a Figura 3.

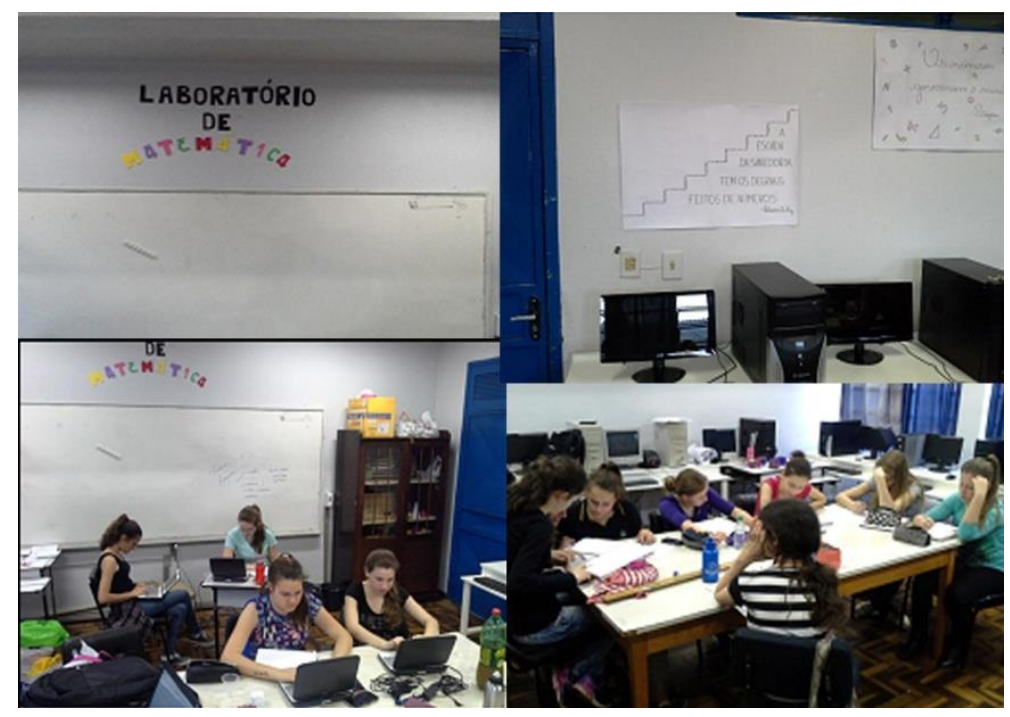

Figura 3 - LABEMAT.

O laboratório, portanto, deve ser um ambiente que desperte no aluno o gosto pela Matemática, a perseverança na busca de soluções e a confiança em sua capacidade de aprender e fazer matemática. Além de contribuir para a construção de conceitos, procedimentos e habilidades matemáticas, propicia a busca de relações, propriedades e regularidades, estimulando o espírito investigativo. Por isso, neste local se respira Matemática o tempo todo, sendo um espaço permanente de busca e descoberta.

Muitos pretextos são criados ao redor da figura do LEM, que precisa de muito investimento, que os jogos só retardam o aprendizado, que expõe as deficiências do professor, que é difícil de montar. Mas o que se percebe em grande parte é o desconhecimento da real importância do LEM na aprendizagem dos alunos, o desconforto que exige o novo desafio, criando uma repulsa pela insegurança de desbravar caminhos nunca percorridos. 
Todos os desafios que foram se delimitando ao longo da execução do projeto foram estímulos importantes para dar continuidade a este trabalho, pois fizeram transcender ainda mais a importância da existência deste espaço na escola e sua consubstancial importância para o ensino de matemática, não somente para o entendimento da teoria aliada a estes materiais, mas da sua contribuição para o desenvolvimento de competências e habilidades fundamentais ao desenvolvimento da cidadania do aluno.

Assim, um projeto que nasceu com o intuito de consolidar um espaço importante na escola para o processo de ensino e aprendizagem de matemática trouxe resultados relevantes decorridos três anos de sua implementação, pois a escola teve um olhar diferenciado para o ensino, organizando espaços (laboratórios) para cada área do conhecimento (linguagens, humanas, natureza, etc.), numa perspectiva que iniciou com o projeto do LABEMAT.

\section{LEM - POTENCIALIDADES PARA O TRABALHO DOCENTE A PARTIR DE EXCERTOS DOS PROFESSORES}

A escola desempenha um papel fundamental na formação e desenvolvimento do indivíduo preparando-o para viver na coletividade, atuando no mundo em que vive a partir de valores éticos e morais. Para tanto, se faz necessário uma organização escolar que leve em consideração o desenvolvimento de competências e habilidades inerentes a compreensão da cidadania como participação social e política, dotada de democracia e liberdade, pautada na autonomia crítica para o desenvolvimento do conhecimento individual de cada aluno.

Nesta perspectiva, os professores de matemática são desafiados constantemente a repensar o processo de ensino, pois aos avanços tecnológicos se acrescentam as questões de desenvolvimento do aluno, exigindo mudança na forma de ensinar, pois o aluno deseja que a construção do saber se torne mais atrativo e prazeroso, trazendo significação ao conhecimento aprendido, além da proficuidade daquele aprendizado para sua vida. Logo, a necessidade de um espaço que dispunha de materiais e instrumentos apropriados para o sucesso do trabalho do professor, visto que a sala de aula comumente usada, por si só não dispunha destes elementos pertinentes ao ensino, se fazendo necessário a organização de espaços diferenciados que possam oportunizar a 
construção do conhecimento mediante interações dinâmicas entre aluno e professor, trazendo significação aos conteúdos trabalhados.

Portanto, emerge a necessidade de repensar a prática docente, transcendendo barreiras e paradigmas que perpetuam a forma de ensinar e não correspondem às necessidades atuais do aluno, trazendo um distanciamento entre o que se ensina e o que se aprende. Para a aproximação entre este ensinar e aprender é preciso descentralizar o ensino da figura única e exclusiva do professor, trazendo autonomia na construção do saber a cada aluno.

Pensando nessas mudanças que surge a figura do Laboratório de Matemática como um espaço de reflexão, investigação, reconhecimento de relações a partir de objetos e/ou contextos que fazem o pensar matemático acontecer, facilitando a compreensão dos conteúdos matemáticos trabalhados.

Existem várias concepções sobre o Laboratório de Ensino de Matemática. Passos(2000) diz que a primeira ideia que ocorre ao se falar de um laboratório na escola é de um ambiente destinado a realizar experiências. Porém sua implementação não é algo a ser conquistado em curto prazo (LORENZATO, 2006). Mas é preciso iniciar este movimento no intuito de:

a) estreitar as relações entre a instituição e a comunidade, atuando como parceira na solução dos problemas educacionais que esta apresenta, buscando a melhoria do ensino e constituindo um espaço de divulgação e de implantação de uma cultura de base científica;

b) estimular a prática da pesquisa em sala de aula, baseada em uma sólida formação teórica e prática; e

c) firmar projetos de parceria com os sistemas locais de ensino, visando à instalação de clubes e laboratórios de Matemática, além de oficinas e cursos de formação continuada para seus professores. (RÊGO; RÊGO, 2012, p.41).

Assim, a formação continuada é fundamental para que o laboratório continue em uso, exigindo que o professor esteja em constante aprendizado, trazendo para aquele espaço alternativas de ensino que sejam condizentes com o momento atual. Afinal, não basta a escola possuir um LEM, é preciso que o professor explore os instrumentos e materiais nele existentes no desenvolvimento de sua prática pedagógica.

Com o intuito de verificar se o espaço organizado para o LEM na Escola Estadual de Educação Básica Yeté continua sendo preservado e utilizado, além de saber quais foram suas contribuições para o ensino de matemática e as dificuldades encontradas para dar continuidade ao projeto, foi realizado um questionário para os professores da escola que participaram do projeto. 
O resultado desta pesquisa aponta aspectos que transcendem o objetivo do projeto. Saber que o projeto serviu de inspiração para as demais áreas do conhecimento se organizarem de maneira a construir seus próprios laboratórios, modificando toda a organização pedagógica da escola, conforme descrito na Figura 4, foi muito gratificante.

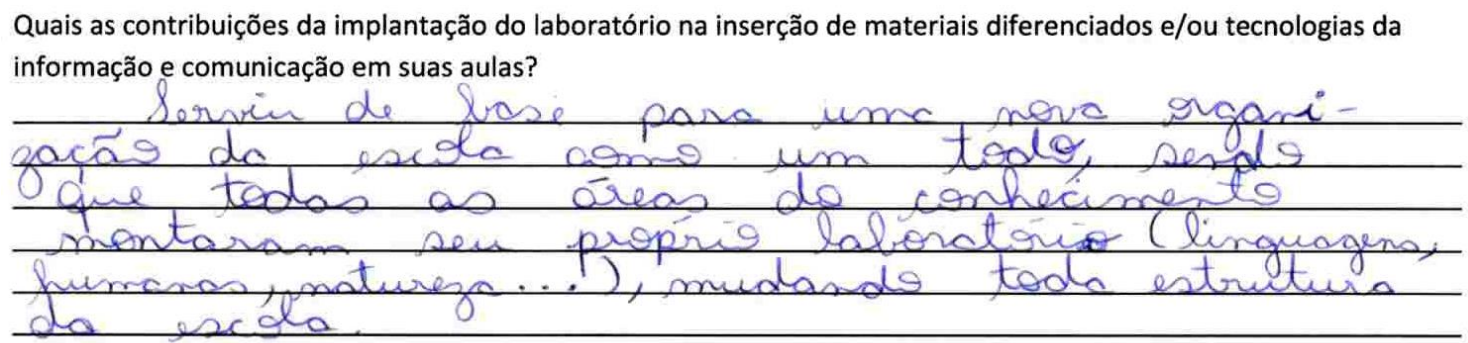

Figura 4 - Questão 5 .

Essa organização por área do conhecimento busca compartilhar conhecimentos que oportunizem a comunicação e a troca de experiências entre os indivíduos inseridos naquele espaço, dando condições para o desenvolvimento de um processo de ensino e aprendizagem participativo, trazendo a luz dos fatos conhecimentos úteis e utilizáveis no cotidiano do aluno.

Além desta mudança significativa na estrutura da escola, o projeto inspirou uma das alunas voluntárias a ingressar no Curso de Licenciatura em Matemática, pela experiência vivida ao longo do projeto, monitorando os trabalhos construídos no laboratório e auxiliando nas atividades desenvolvidas pelos professores com seus alunos, conforme salienta uma professora na Figura 5.

Por esse viés percebe-se a importância de oportunizar vivências aliando teoria à prática, desenvolvendo competências e habilidades importantes para o exercício da cidadania, entendendo que aprender matemática é fundamental para a vida de qualquer pessoa.

O projeto de implantação do laboratório de matemática desenvolvido na sua escola impactou em que aspectos o

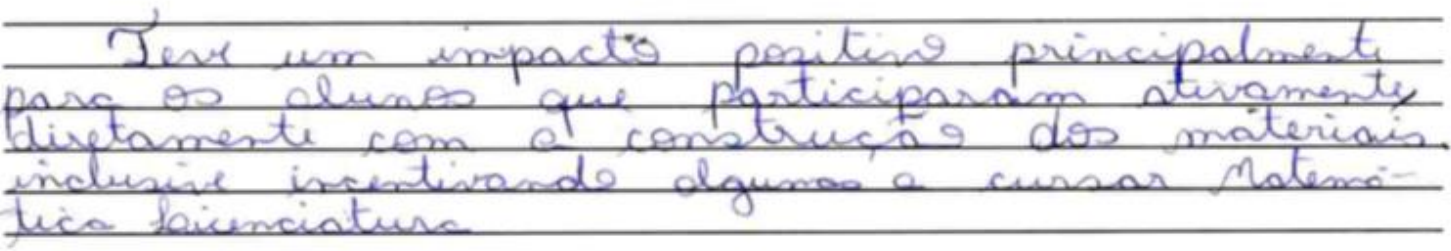


Figura 5 - Questão 1.

Alguns estudos têm discutido sobre as diferentes concepções do LEM, os objetivos de sua organização, a importância deste espaço na formação dos alunos, bem como as diferentes propostas de sua utilização. Assim a necessidade emergente de formação de professores para que estes espaços conquistados sejam preservados e utilizados pelos profissionais na sua integralidade, se incorporando ao ensino de forma efetiva, conforme relato de uma das professoras (Figura 6), que descreve a dificuldade em trabalhar com tecnologias da informação e comunicação.

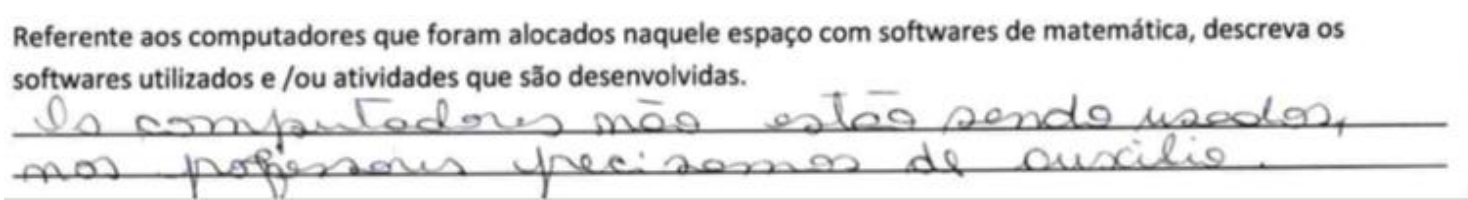

Figura 6 - Questão 4.

Esta dificuldade aponta um caminho importante que pode ser seguido durante a proposta de implementação do LEM nas escolas de Educação Básica: 1) trabalhar o projeto de construção e implementação do espaço; e 2) desenvolver um projeto de formação continuada para os professores (Figura 7). Desta maneira, a proposta de incorporar efetivamente o uso do laboratório ao processo de ensino e aprendizagem de matemática das escolas se integraliza, pois as dificuldades encontradas ao manusear os instrumentos e materiais podem se tornar um entrave para a perpetuação desta prática.

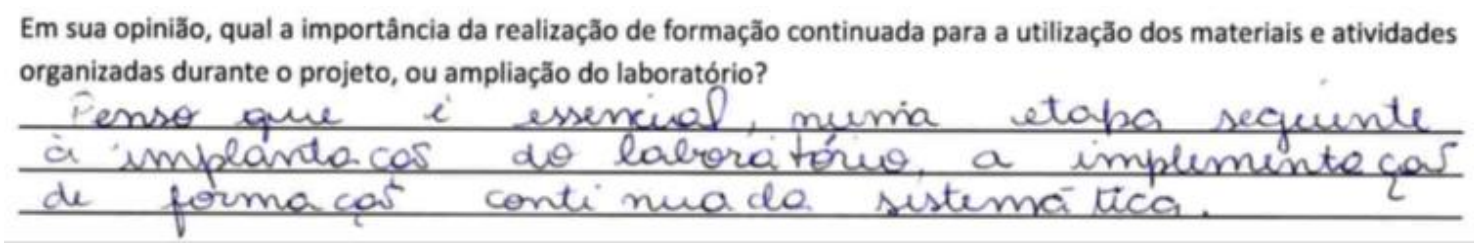

Figura 7 - Questão 7.

Por acreditar nas mudanças que o LEM pode trazer ao processo de ensino e aprendizagem da matemática, ficou evidente na pesquisa a necessidade de formação continuada para os professores, oferecendo subsídios importantes para que o espaço continue sendo atualizado e implementado. Assim, um novo projeto de extensão foi organizado no intuito de contribuir com a formação continuada dos professores de matemática das escolas públicas da região, contemplando o que se apresentou como 
resultado desta pesquisa, permitindo que o trabalho realizado pelo projeto de extensão continue colhendo bons indicativos de aprendizagem matemática nos espaços escolares.

O fato de não se estender por mais tempo caracteriza a importância que o projeto teve para a escola e para os professores, pois mesmo havendo dificuldades com o uso de tecnologias, tendo que se restringir ao uso dos materiais manipuláveis, houve contribuições para o processo de ensino e aprendizagem de matemática, as quais puderam ser observadas pelas demais áreas do conhecimento, levando a direção da escola a realizar uma nova organização didática, mediante a efetivação de laboratórios para cada área do conhecimento.

Assim, o objetivo é fomentar a implementação de Laboratórios de Ensino de Matemática em outras Escolas de Educação Básica da região, motivando os professores que participarão do projeto de formação continuada por meio do depoimento das professoras da Escola Estadual de Educação Básica Yeté onde o projeto do LABEMAT foi realizado. O propósito é oportunizar que os professores sejam os precursores desta iniciativa em suas escolas. A formação continuada lhes oferecerá a oportunidade de construção de materiais, utilização de tecnologias e metodologias de ensino que possam trazer significância a aprendizagem matemática, mas a iniciativa para implementação do LEM deverá emergir dos professores que receberão todo o suporte didático e metodológico para sua realização durante a formação.

\section{CONSIDERAÇÕES FINAIS}

Ainda que ensinar seja uma tarefa árdua, que demanda muita pesquisa, planejamento e dedicação, acredita-se que a partir de pequenas ações é possível fazer com que este movimento de ensinar e aprender possa se transformar. O LEM vem ao encontro deste aforismo, propiciando uma dinâmica de ensino atrativa, promovendo uma interação social importante entre professor e aluno, tornando o estudo mais prazeroso para os alunos, dispondo de materiais e instrumentos fundamentais ao processo de ensino e aprendizagem de qualidade.

Oportunizar processos de experimentação no LEM contribui para um ensino baseado na construção do conhecimento, onde o professor é um mediador do processo, quebrando alguns paradigmas educacionais que contemplam práticas exclusivamente expositivas, que "apesar de alguma inovação nos métodos de ensino, tem-se ficado 
muito aquém do que seria desejável - por vários motivos; um deles é a gestão de espaços educativos e recursos materiais nas escolas" (LIMA, 1995, p.1-2).

Por este viés, a criação do LEM nas Escolas de Educação Básica é uma conquista importante para o ensino de matemática que aos poucos se incorpora a maioria das escolas, que vislumbram resultados importantes para a aprendizagem matemática dos alunos. Professores que buscam inovação nas aulas, explorando materiais e instrumentos que promovam a construção do conhecimento, estimulando a capacidade cognitiva de avaliação, análise e síntese, e não mera memorização de conteúdo. Jan Amos Comenius, líder religioso tcheco, filósofo e o iniciador da pedagogia moderna, no século XVII, afirmava: "É necessário desenvolver um método de ensino em que os professores lecionem menos para que os alunos possam aprender mais".

Este movimento de transformar a escola em um lugar de descoberta se efetiva quando o professor entende a real importância que o laboratório tem na aprendizagem, promovendo aulas que oportunizem a exploração dos materiais e instrumentos contidos nele, estimulando a capacidade cognitiva do aluno. Por isso, não basta que o espaço exista, é essencial que os professores façam uso e busquem formação continuada para inovar sua ação docente, pois " o ambiente social e a situação que o professor cria são cruciais no desenvolvimento lógico matemático" (KAMII, 1994, p.63).

Conforme Piaget, Vygotsky e Freire, o que caracteriza a aprendizagem é o movimento de "um saber fazer" para "um saber", por meio de uma abstração reflexiva onde o indivíduo pensa na ação e estabelece alguma teoria que explique os resultados alcançados. Neste sentido a importância da experimentação para que o processo de transposição ocorra, trazendo significação ao conteúdo trabalhado, privilegiando o LEM como um ambiente onde o aluno possa analisar, conjecturar, questionar, verificar, compreender e validar a construção do seu conhecimento, podendo desenvolver este processo no seu tempo, de maneira individual e natural.

Diante do exposto entende-se que o projeto foi apenas uma semente plantada e da qual muitos frutos ainda serão colhidos. Os resultados obtidos mostram que a implementação do LEM trouxe um olhar diferenciado para aquela comunidade escolar, mas que precisa de formação continuada dos professores para dar vida longa ao que foi iniciado pelo projeto. Para consolidar ainda este trabalho e oportunizar sua perpetuação para outras escolas, emerge a necessidade de, juntamente com novas implementações, oportunizar a formação continuada de professores de matemática, difundindo o que vem 
sendo pesquisado e experimentado pelas instituições de formação inicial de modo a contribuir com a consolidação de novos LEM em Escolas de Educação Básica.

\section{REFERÊNCIAS}

BRASIL. Secretaria de Educação Fundamental. Parâmetros Curriculares Nacionais: Matemática. Rio de Janeiro: DP\&A, 2000.

D’AMBRÓSIO, U. Matemática, ensino e educação: uma proposta global. Temas \& Debates, São Paulo, 1991.

KAMII, C.; DeCLARK, G. Reinventando a Aritmética: implicações da teoria de Piaget. São Paulo: Papirus, 1994.

LIMA, E.. Sobre o Ensino da Matemática. Revista do Professor de Matemática, n 28, p. 5, 2 quadrimestre de 1995 .

LORENZATO, S. Laboratório de ensino de matemática e materiais didáticos manipuláveis. IN: LORENZATO, Sérgio (Org.). O Laboratório de Ensino de Matemática na Formação de Professores. 3 ed. Campinas, SP: Autores Associados, 2012. (Coleção formação de professores)

LOREnZATO, S. Para Aprender Matemática. 2 ed. rev. Campinas, SP: Autores Associados, 2008. (Coleção formação de professores)

PASSOS, C.L.B.; GRANDO, R.C. Laboratório de Ensino de Matemática. Texto fotocopiado. Campinas, 2000.

QUEIROZ, A. M. N. P. A Matemática Transparente: ao alcance de todos. São Paulo: Editora Livraria da Física, 2011.

PIAGET, J. A teoria de Piaget. In: MUSSEN, P. H. (org). Psicologia da criança. Desenvolvimento Cognitivo. São Paulo: E.P.U. 1975. Vol. 4, p. 71-117.

RÊGO, R. M.; RÊGO, R. G. Desenvolvimento e uso de materiais didáticos no ensino de matemática. In: LORENZATO, Sérgio. Laboratório de Ensino de Matemática na formação de professores. Campinas: Autores Associados, 2012. p. 39-56.

SÁ, P. F. et al. O ensino das operações com frações a partir de situações-problema. IN: SÁ, P. F.; JUCÁ, R. S. (Org.). Matemática por atividades: experiências didáticas 